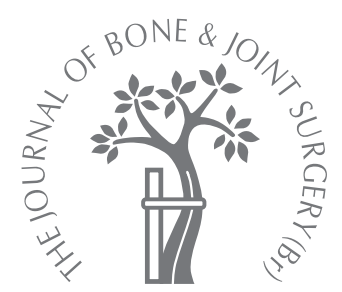

\title{
Treatment of failed arthroscopic acetabular labral debridement by femoral chondro- osteoplasty
}

\author{
A CASE SERIES OF FIVE PATIENTS
}

O. May,

W. Y. Matar,

P. E. Beaulé

From the University

of Ottawa, Ontario, Canada
ㄷ. May, MSc, MD, Fellow in Orthopaedic Surgery Service d'Orthopédie $C$ Hôpital Roger Salengro Université Lille 2, 59037 Lille Cedex, France.

W. Y. Matar, MSc, MD, Orthopaedic Surgery Resident (PGY-4)

I. E. Beaulé, MD, FRCSC, Associate Professor

University of Ottawa, Ottawa Hospital - General Campus, 501 Smyth Road, Room 5004, Ottawa, Ontario, Canada K1H $8 \mathrm{~L} 6$.

Correspondence should be sent to $\operatorname{Dr}$ P. E. Beaulé; e-mail: pbeaule@ottawahospital.on.ca

(C)2007 British Editorial Society of Bone and Joint Surgery doi:10.1302/0301-620X.89B5. $18753 \$ 2.00$

$J$ Bone Joint Surg $[\mathrm{Br}]$ 2007;89-B:595-8.

Received 6 October 2006 Accepted after revision 8 January 2007

\begin{abstract}
Femoroacetabular impingement is recognised as being a cause of labral tears and chondral damage. We report a series of five patients who presented with persistent pain in the hip after arthroscopy for isolated labral debridement. All five had a bony abnormality consistent with cam-type femoroacetabular impingement. They had a further operation to correct the abnormality by chondro-osteoplasty of the femoral head-neck junction. At a mean follow-up of 16.3 months (12 to 24 ) all had symptomatic improvement.
\end{abstract}

Labral tears cause pain in the hip. In the last decade, our understanding of such tears and the pain they can cause has improved. Lage, Patel and Villar ${ }^{1}$ described four types of labral tear based on its aetiology: degenerative, traumatic, congenital and idiopathic. This classification has since been modified as a result of studies on femoroacetabular impingement $\mathrm{t}^{2,3}$ and its association with chondral damage and labral tears. ${ }^{4-6}$ Thus, an impinging category has been defined and has replaced, for the most part, the idiopathic group. Two recent reports by Peelle et $\mathrm{al}^{5}$ and Wenger et $\mathrm{al}^{6}$ have shown that labral tears are commonly associated with bony abnormalities, such as a lack of anterior head-neck offset, an aspherical femoral head, or a retroverted acetabulum. In addition, most hips with labral tears have associated chondral damage of the acetabulum, ${ }^{4,7}$ which may explain the mixed results of isolated arthroscopic debridement. ${ }^{8-11}$ There is also mounting evidence that this chondral damage is not secondary to the labral tear but is associated with femoroacetabular impingement. ${ }^{4,12,13}$ Although the initial clinical results on the treatment of impingement have been encouraging, ${ }^{13-15}$ there is still some controversy as to which aspect of the treatment (correction of the bony abnormality, labral debridement or both), provides the best clinical outcome.

We report a series of five patients who presented with persistent pain in the hip after arthroscopic labral debridement and who subsequently underwent correction of the bony abnormality associated with femoroacetabular impingement.

\section{Patients and Methods}

There were three women and two men with a mean age of 40 years (27 to 48 ). The operative reports of the arthroscopy confirmed the presence of labral tears which had been treated by isolated labral debridement. No cartilage delamination was noted in any of the reports. The mean time to consultation with the senior author (PEB) after arthroscopy was 13.6 months (6 to 18$)$. All the patients had a positive impingement sign on physical examination. ${ }^{16}$ The University of California Los Angeles (UCLA) hip score st,18 $^{17}$ was used to assess pain, walking, function and activity.

Radiological evaluation consisted of anteroposterior (AP) pelvic and cross-table lateral radiographs (Fig. 1). ${ }^{19}$ Although the AP radiographs had not been standardised to meet the criteria of Siebenrock, Kalbermatten and Ganz, ${ }^{20}$ acetabular retroversion was not seen in any case. All the patients had further MRI with gadolinium arthrography. ${ }^{21}$ In four, a persistent labral tear was seen. The fifth patient had complete labral excision in the anterosuperior quadrant. On the radial reformations of MRI, the $\alpha$ angle of Notzli et $\mathrm{al}^{22}$ was a mean of $80.8^{\circ}\left(66^{\circ}\right.$ to $\left.95^{\circ}\right)$. On the cross-table lateral radiograph, the offset ratio of Eijer et $\mathrm{al}^{23}$ was a mean of $0.10(0.08$ to 0.14$)$ (Table I).

All five patients had further surgery when the MRI findings were confirmed (Fig. 2). All had associated acetabular chondral damage of type 4 as described by Beck et al. ${ }^{13}$ Each underwent chondro-osteoplasty of the femoral headneck junction and repeat debridement of the torn labrum. The classic surgical dislocation 


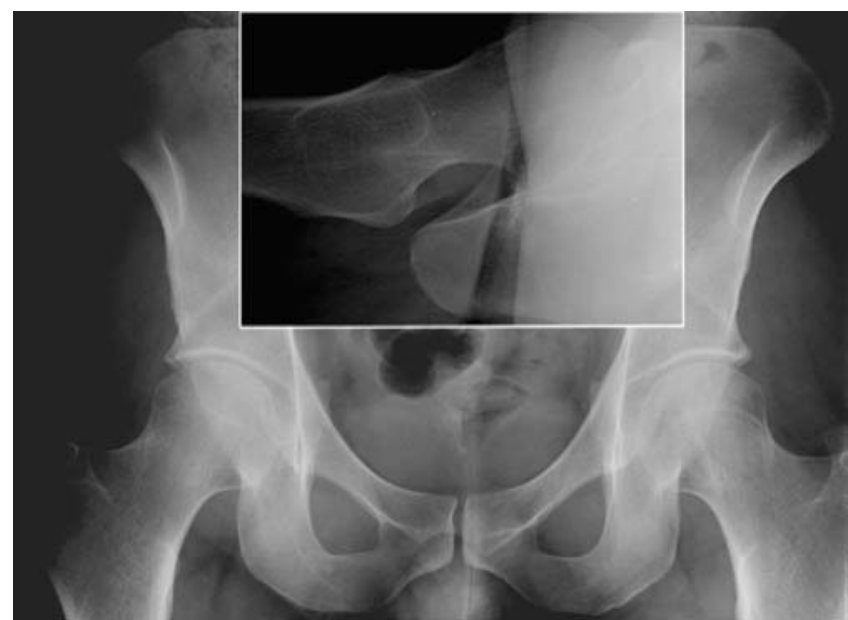

Fig. 1

Pre-operative anteroposterior pelvic and (inset) cross-table lateral radiographs of a 38-year-old man. The femoral head appears spherical in the coronal plane illustrating the importance of determining the lack of anterior concavity in the sagittal plane.

approach of Ganz et al ${ }^{24}$ (Fig. 3) was used in three cases. The other two had a combination of arthroscopy of the hip and labral debridement with anterior arthrotomy, through which the chondro-osteoplasty was performed under direct visualisation. ${ }^{25,26}$ This was done to avoid a more extensive soft-tissue dissection. None of the patients required labral re-fixation with rim trimming because of the absence of acetabular retroversion. Weight-bearing was restricted for four to six weeks.

Statistical analysis. The difference between the pre-operative and follow-up hip scores was analysed using Student's $t$-test. Statistical significance was determined as a $\mathrm{p}$-value $<0.05$.

\section{Results}

There were no post-operative complications. One patient required the removal of screws because of painful internal fixation, after which the symptoms resolved. At a mean follow-up of 16.3 months (12 to 24 ), all the patients had symptomatic improvement (Table II). The mean UCLA hip score improved as follows: pain, from 3 (1 to 6$)$ to 7 (6 to 9) $(\mathrm{p}=0.01)$; walking, from 8 to 9.2 ( 8 to 10$)(\mathrm{p}=0.07)$; function, from 5.8 ( 1 to 8 ) to 8 (4 to 10$)$ ( $\mathrm{p}=0.00)$; and activity, from 6 (2 to 10$)$ to 7 (4 to 10$)(\mathrm{p}=0.03)$.

\section{Discussion}

Before the description of femoroacetabular impingement, isolated labral tears, diagnosed by means of hip $\operatorname{arthroscopy~}^{27}$ and/or MRI with arthrography, ${ }^{21,28}$ had been identified as a primary cause of pain in the hip. 9,29 These tears were usually categorised as idiopathic ${ }^{1,29}$ or secondary to minor trauma. The reason for this was in part due to the fact that assessment of hip morphology was performed only in the coronal plane, while very often the major deformity in femoroacetabular impingement was in the sagittal plane. ${ }^{23,30}$ The anterolateral head-neck junction was also not systematically examined in the peripheral compartment. Because the initial results of treatment of isolated labral tears were encouraging, this left some uncertainty as to the need for correcting a co-existing bony abnormality. ${ }^{10,31,32}$ Our data support the added clinical benefit in correcting pre-existing bony dysmorphism in the presence of labral pathology and provides additional clinical evidence that an uncorrected bony abnormality consistent with femoroacetabular impingement can lead to the failure of isolated labral debridement. Although in the initial early experience of the treatment of femoroacetabular impingement, there were good to excellent results in only $65 \%$ to $68 \%$ of patients, ${ }^{13,14}$ more recent series in which the labrum has not been resected, have had a better

Table I. Clinical details and radiological findings in the five patients

\begin{tabular}{llllllll}
\hline Case & Gender & Age (yrs) & Side & $\begin{array}{l}\text { Time after hip } \\
\text { arthroscopy } \\
\text { (mths) }\end{array}$ & $\begin{array}{l}\text { Impingement } \\
\text { sign }\end{array}$ & $\begin{array}{l}\text { Offset } \\
\text { ratio }\end{array}$ & $\begin{array}{l}\boldsymbol{\alpha} \text { angle } \\
\left({ }^{\circ}\right)\end{array}$ \\
\hline 1 & Male & 27 & Right & 14 & Positive & 0.10 & 90 \\
2 & Male & 38 & Right & 18 & Positive & 0.08 & 66 \\
3 & Female & 43 & Right & 6 & Positive & 0.08 & 80 \\
4 & Female & 48 & Right & 12 & Positive & 0.12 & 95 \\
5 & Female & 44 & Right & 18 & Positive & 0.14 & 73 \\
\hline
\end{tabular}

Table II. Individual University of California Los Angeles hip scores in the five patients before and after operation

\begin{tabular}{|c|c|c|c|c|c|c|c|c|}
\hline \multirow[b]{2}{*}{ Case } & \multicolumn{2}{|l|}{ Pain } & \multicolumn{2}{|l|}{ Walking } & \multicolumn{2}{|l|}{ Function } & \multicolumn{2}{|l|}{ Activity } \\
\hline & Pre-operative & Post-operative & Pre-operative & Post-operative & Pre-operative & Post-operative & Pre-operative & Post-operative \\
\hline 1 & 6 & 9 & 8 & 10 & 8 & 10 & 8 & 9 \\
\hline 3 & 2 & 6 & 8 & 10 & 6 & 8 & 7 & 8 \\
\hline 4 & 2 & 8 & 8 & 10 & 6 & 8 & 3 & 4 \\
\hline 5 & 4 & 6 & 8 & 8 & 8 & 10 & 10 & 10 \\
\hline
\end{tabular}




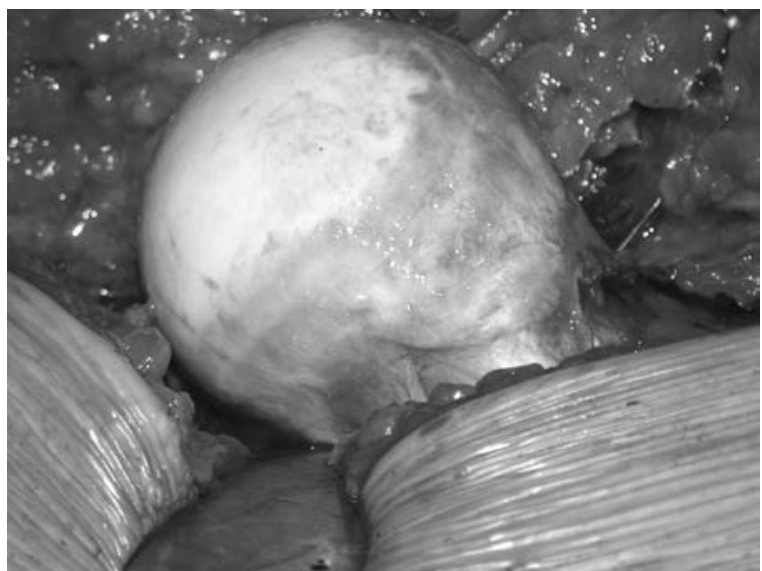

Fig. 2a

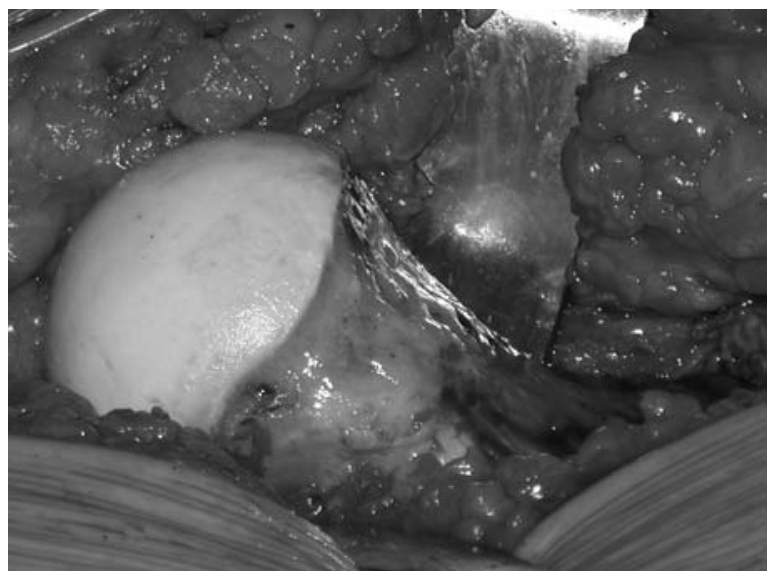

Fig. $2 b$

Intra-operative views of a) the insufficient concavity of the femoral head-neck junction and b) after treatment by chondro-osteoplasty.

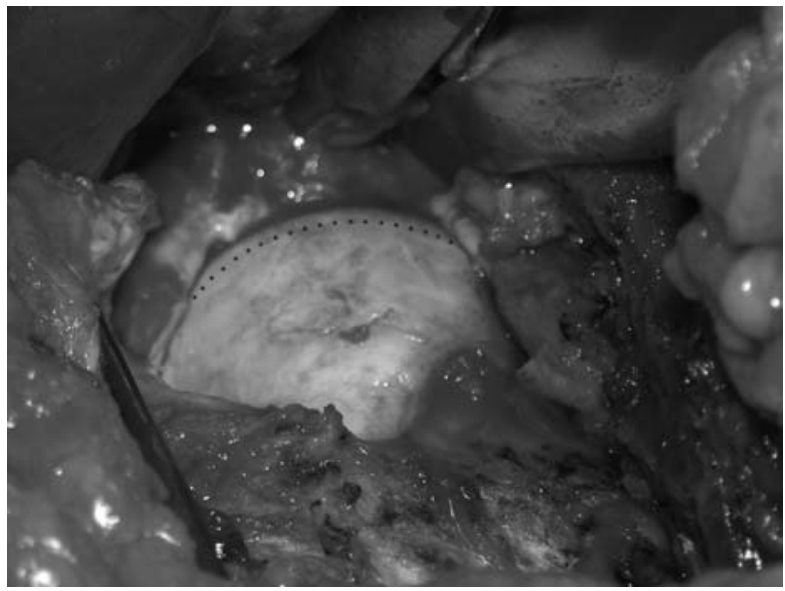

Fig. 3a

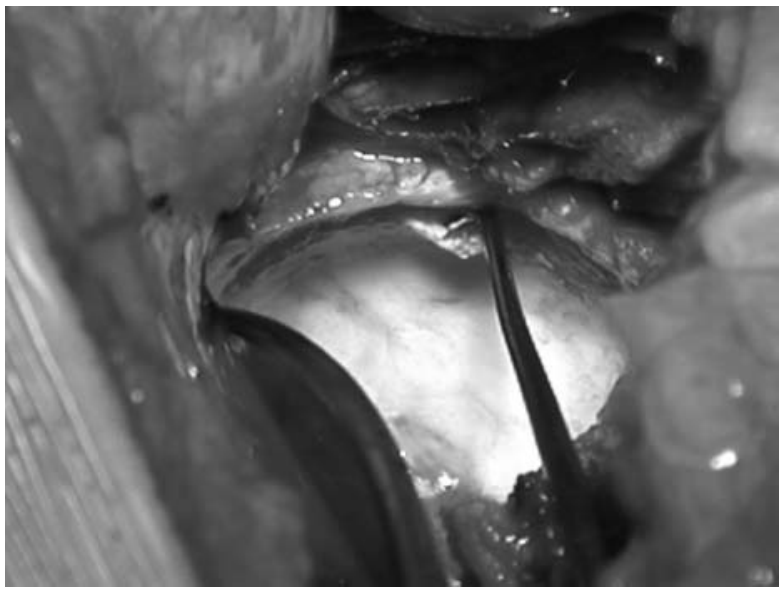

Fig. 3b

Intra-operative views showing a) the partially excised labrum (dotted line) and b) associated cartilage flap of the acetabulum.

outcome, with over $80 \%$ of patients showing significant improvement in their hip function. ${ }^{15,33}$ However, despite an improvement in function, three of our five patients still had pain with activity which required the occasional use of antiinflammatory agents. It is difficult to speculate why these three patients had more pain than the other two, but this may be related to the amount of remaining labrum after the initial labral debridement as well as the extent of chondral damage. When Espinosa et $\mathrm{al}^{15}$ compared the outcome of patients treated for femoroacetabular impingement by open surgery, those who had labral refixation did significantly better than those with resection. None of the patients in our series underwent labral refixation nor did they undergo further labral resection. Currently, we perform labral refixation in the presence of acetabular retroversion and/or with a delamination flap extending beyond $5 \mathrm{~mm}$. A study by Ferguson et $\mathrm{al}^{34}$ suggested that the labrum may act more as a seal, ensuring a more constant fluid film for lubrication and limiting the rate of expression of fluid from the articular cartilage. This occurs by preventing fluid flow, tangential to the cartilage surfaces, through the interarticular gap and by increasing the length of the fluid flow path through the labrum. Based on this model, complete or partial excision of the labrum is likely to disrupt the sealing effect, thus putting the cartilage surfaces at risk of premature wear. In addition, even in the presence of a partial tear with femoroacetabular impingement, recent work by Ito, Leunig and Ganz ${ }^{35}$ has shown that the tip of the labrum remains intact, thus potentially maintaining its function as a fluid sealant.

There remains the unresolved issue as to how much bony abnormality is acceptable in the presence of a damaged labral-chondral complex. ${ }^{36}$ This is especially true for dysplasia or femoroacetabular impingement in which osteo- 
tomy of the pelvis ${ }^{37}$ or surgical dislocation and chondroosteoplasty ${ }^{24}$ are the standard procedures. In addition, although it is now well known that most labral tears are associated with a structural bony abnormality, ${ }^{5,6}$ there is little information on how correcting a bony abnormality can improve outcome. We believe that our report provides evidence to support re-operation after failed isolated labral debridement in the presence of femoroacetabular impingement, and stresses the importance of assessing hip morphology in both the coronal and sagittal planes. As less invasive surgical techniques such as hip arthroscopy are perfected, the question of correcting a bony abnormality associated with femoroacetabular impingement ${ }^{38}$ may become less of an issue.

No benefits in any form have been received or will be received from a commercial party related directly or indirectly to the subject of this article.

\section{References}

1. Lage LA, Patel JV, Villar RN. The acetabular labral tear: an arthroscopic classification. Arthroscopy 1996;12:269-72.

2. Ganz R, Parvizi J, Leunig M, et al. Femoroacetabular impingement: a cause for osteoarthritis of the hip. Clin Orthop 2003;417:112-20.

3. Leunig M, Podeszwa D, Beck M, Werlen S, Ganz R. Magnetic resonance arthrography of labral disorders in hips with dysplasia and impingement. Clin Orthop 2004; $418: 74-80$

4. Beck M, Kalhor M, Leunig M, Ganz R. Hip morphology influences the pattern of damage to the acetabular cartilage: femoroacetabular impingement as a cause of early osteoarthritis of the hip. J Bone Joint Surg [Br] 2005;87-B:1012-18.

5. Peelle MW, Della Rocca GJ, Maloney WJ, Curry MC, Clohisy JC. Acetabular and femoral radiographic abnormalities associated with labral tears. Clin Orthop 2005;441:327-33.

6. Wenger DE, Kendall KR, Miner M, Trousdale RT. Acetabular labral tears rarely occur in the absence of bony abnormalities. Clin Orthop 2004;426:145-50.

7. McCarthy JC, Noble PC, Schuck MR, Wright J, Lee J. The Otto E. Aufranc Award: the role of labral lesions to development of early degenerative hip disease. Clin Orthop 2001:393:25-37.

8. Farjo LA, Glick JM, Sampson TG. Hip arthroscopy for acetabular labral tears. Arthroscopy 1999;15:132-7.

9. Fitzgerald RH Jr. Acetabular labrum tears: diagnosis and treatment. Clin Orthop 1995;311:60-8.

10. Byrd JW, Jones KS. Prospective analysis of hip arthroscopy with 2-year follow-up. Arthroscopy 2000;16:578-87.

11. Santori N, Villar RN. Acetabular labral tears: result of arthroscopic partial limbectomy. Arthroscopy 2000;16:11-15

12. Leunig M, Casillas MM, Hamlet M, et al. Slipped capital femoral epiphysis: early mechanical damage to the acetabular cartilage by impingement of a prominent femoral metaphysis. Acta Orthop Scand 2000;71:370-5.

13. Beck M, Leunig M, Parvizi J, et al. Anterior femoroacetabular impingement. Part II: midterm results of surgical treatment. Clin Orthop 2004;418:67-73.

14. Murphy S, Tannast M, Kim YJ, Buly R, Millis MB. Debridement of the adult hip for femoroacetabular impingement: indications and preliminary clinical results. Clin Orthop 2004:429:178-81.
15. Espinosa N, Rothenfluh DA, Beck M, Ganz R, Leunig M. Treatment of femoroacetabular impingement: preliminary results of labral refixation. J Bone Joint Surg [Am]2006;88-A:925-35.

16. Klaue K, Durnin CW, Ganz R. The acetabular rim syndrome: a clinical presentation of dysplasia of the hip. J Bone Joint Surg [Br] 1991;73-B:423-9.

17. Amstutz HC, Thomas BJ, Jinnah R, et al. Treatment of primary osteoarthritis of the hip: a comparison of total joint and surface replacement arthroplasty. $J$ Bone Joint Surg [Am] 1984;66-A:228-41.

18. Beaule PE, Dorey FJ, Hoke R, Leduff M, Amstutz HC. The value of patient activity level in clinical outcome of total hip arthroplasty. J Arthroplasty 2006;21:547-52.

19. Zaragoza EJ, Beaule PE. Imaging of the painful non-arthritic hip: a practical approach to surgical relevancy. Oper Tech Orthop 2004;14:42-8.

20. Siebenrock KA, Kalbermatten DF, Ganz R. Effect of pelvic tilt on acetabular retroversion: a study of pelves from cadavers. Clin Orthop 2003;407:241-8.

21. Leunig M, Werlen S, Ungersbock A, Ito K, Ganz R. Evaluation of the acetabular labrum by MR arthrography. J Bone Joint Surg [Br] 1997;79-B:230-4.

22. Notzli HP, Wyss TF, Stoecklin CH, et al. The contour of the femoral head-neck junction as a predictor for the risk of anterior impingement. J Bone Joint Surg $[\mathrm{Br}]$ 2002;84-B:556-60.

23. Eijer H, Leunig M, Mahomed N, Ganz R. Cross-table lateral radiographs for screening of anterior femoral head-neck offset in patients with femoro-acetabular impingement. Hip International 2001;11:37-41.

24. Ganz R, Gill TJ, Gautier E, et al. Surgical dislocation of the adult hip: a technique with full access to the femoral head and acetabulum without the risk of avascular necrosis. J Bone Joint Surg [Br] 2001;83-B:1119-24.

25. Sekiya JK, Wojtys EM, Loder RT, Hensinger RN. Hip arthroscopy using a limited anterior exposure: an alternative approach for arthroscopic access. Arthroscopy 2000;16:16-20.

26. Clohisy JC, McClure JT. Treatment of anterior femoroacetabular impingement with combined hip arthroscopy and limited anterior decompression. lowa Orthop J 2005;25:164-71.

27. Suzuki S, Awaya G, Okada Y, et al. Arthroscopic diagnosis of ruptured acetabular labrum. Acta Orthop Scand 1986;57:513-15.

28. Czerny C, Hofmann S, Neuhold A, et al. Lesions of the acetabular labrum: accuracy of MR imaging and MR arthrography in detection and staging. Radiology 1996;200:225-30

29. Byrd JW. Labral lesions: an elusive source of hip pain case reports and literature review. Arthroscopy 1996;12:603-12.

30. Ito K, Minka MA 2nd, Leunig M, Werlen S, Ganz R. Femoroacetabular impingement and the cam-effect: a MRI-based quantitative anatomical study of the femoral head-neck offset. J Bone Joint Surg [Br] 2001;83-B:171-6.

31. McCarthy J, Noble P, Aluisio FV, et al. Anatomy, pathologic features, and treatment of acetabular labral tears. Clin Orthop 2003;406:38-47.

32. O'Leary JA, Berend K, Vail TP. The relationship between diagnosis and outcome in arthroscopy of the hip. Arthroscopy 2001;17:181-8.

33. Peters CL, Erickson JA. Treatment of femoro-acetabular impingement with surgical dislocation and debridement in young adults. J Bone Joint Surg [Am] 2006;88A:1735-41.

34. Ferguson SJ, Bryant JT, Ganz R, Ito K. An in vitro investigation of the acetabular labral seal in hip joint mechanics. J Biomech 2003;36:171-8.

35. Ito K, Leunig M, Ganz R. Histopathologic features of the acetabular labrum in femoroacetabular impingement. Clin Orthop 2004;429:262-71.

36. McCarthy JC, Mason JB, Wardell SR. Hip arthroplasty for acetabular dysplasia: a pipe dream? Orthopedics 1998;21:977-9.

37. Siebenrock KA, Scholl E, Lottenbach M, Ganz R. Bernese periacetabular osteotomy. Clin Orthop 1999:363:9-20.

38. Crawford JR, Villar RN. Current concepts in the management of femoroacetabular impingement. J Bone Joint Surg [Br] 2005;87-B:1459-62 